International Journal of Medical Anesthesiology 2020; 3(1): 219-223

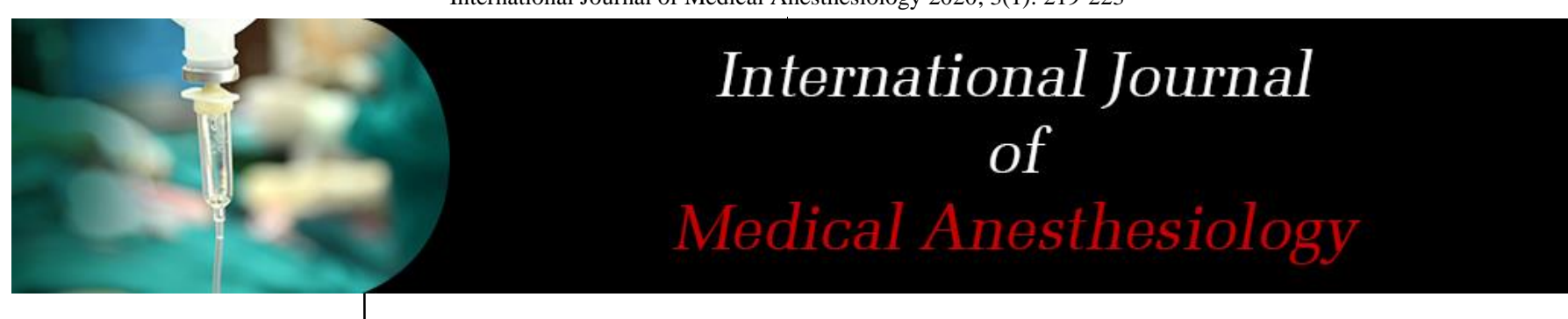

E-ISSN: 2664-3774

P-ISSN: 2664-3766

www.anesthesiologypaper.com

IJMA 2020; 3(1): 219-223

Received: 01-11-2019

Accepted: 04-12-2019

Shaikh Mohd Mudassir

Assistant professor Department

of Anaesthesiology, Indian

Institute of Medical Sciences and

Research, Warudi Jalna,

Maharashtra, India

Dr. Jitendra Raghunath

Waghmare

Associate Professor Department

of Anaesthesia, PCMC PGI YCM

Hospital Pimpri, Pune,

Maharashtra, India
Corresponding Author: Dr. Jitendra Raghunath Waghmare

Associate Professor Department of Anaesthesia, PCMC PGI YCM

Hospital Pimpri, Pune,

Maharashtra, India

\section{A comparative study of spinal anaesthesia versus epidural anaesthesia for inguinal hernioplasty}

\author{
Shaikh Mohd Mudassir and Dr. Jitendra Raghunath Waghmare
}

DOI: $\underline{\text { https://doi.org/10.33545/26643766.2020.v3.i1d.91 }}$

\begin{abstract}
Introduction: Inguinal hernia repair is normally implemented under spinal anaesthesia. However, epidural anaesthesia procedure offers constant hemodynamic with early ambulation and less urinary retention, less frequency of nausea and vomiting. We compared efficacy, feasibility and safety of ilioinguinal nerve block for inguinal hernia repair with spinal anaesthesia versus epidural anaesthesia.

Material and methods: Hundred adult male patients scheduled for elective inguinal hernia repair were randomized into two groups to receive either spinal anaesthesia or epidural anaesthesia. The total time to perform anaesthetic procedures, time of onset, hemodynamic variations, supplemental sedation, intraoperative fluid requirement, duration of postoperative analgesia and ambulation were compared in both groups. Continuous data are presented as mean \pm S.D. Unpaired $t$-test and paired $t$-test were applied for intergroup and intragroup comparisons respectively. $P<0.05$ was taken as significant.

Results: Duration to perform the procedure was significantly longer with epidural than spinal block (7.95 $\pm 0.41 \mathrm{Vs} 3.73 \pm 0.67$ minutes). Intraoperative fluid requirement was statistically higher in Spinal than Epidural $(1580 \pm 190.1 \mathrm{ml}$ vs $1021.33 \pm 77.16 \mathrm{ml})(p<0.0001)$. Duration of Surgery was significantly shorter in Spinal as compared to Epidural $(85.17 \pm 7.82$ vs $101.00 \pm 10.20$ mins.) $(\mathrm{p}=0.019)$. Systolic and mean blood pressure showed statistically significant reduction in Spinal as compared to Epidural (19(40\%) vs 3(6\%)) ( $p<0.001)$.

Duration of ambulation was significantly shorter in Epidural as compared to Spinal (3.95 \pm 2.57 vs $9.58 \pm 0.82$ hours $)(p<0.001)$.

Conclusion: Epidural anaesthesia can be a safe alternative to spinal anaesthesia for elective inguinal hernia repair.
\end{abstract}

Keywords: Epidural anaesthesia, Spinal anaesthesia, inguinal hernia repair

\section{Introduction}

Hernia is a common surgical problem which needs good surgical skill in addition to deep knowledge about anatomy and numerous technique repair of hernia. Hernia is a protrusion of a viscous or part of viscous through a normal or abnormal opening in the wall of its comprising cavity. The hernia term is originated from Greek meaning an offshoot, a budding, or bulge ${ }^{[1]}$. The Latin term hernia means a rupture or tear. The external abdominal hernia is the most common form; the maximum recurrent variability existence the inguinal, femoral and the umbilical, accounting for $75 \%$ of cases. The rarer form founds $1.5 \%$, excluding incisional hernia ${ }^{[2]}$.

Inguinal hernia is one of the main surgeries in universal operation rooms. The goal of all these surgeries is repair, decrease reappearance, postoperative pain, and expense and find out the most consistent and valued techniques ${ }^{[3]}$. There are various types of anaesthesia including epidural, local, spinal, and general anaesthesia procedures have been used, from time to time each having its own benefits and drawbacks ${ }^{[4]}$.

Spinal anesthesia has been found to be a well-known technique for inguinal hernia surgeries as it is easy to do, and delivers quick onset of action, effective sensory and motor blockade in a conscious patient ${ }^{[5]}$. It also prevents hemodynamic and airway manipulation complications concomitant with general anesthesia ${ }^{[6]}$. Spinal anaesthesia, though effective, is not without risk in patients with decompensated heart disease, convulsions, recent head injury, and coagulopathies. Also, spinal and epidural anaesthesia (EA) have been accompanying with hemodynamic variability, urinary retention, vomiting, post dural puncture headache, and backache ${ }^{[7]}$. 
The aim of this analysis was to assess achievement, efficacy, feasibility and safety of spinal and epidural anaesthesia with single puncture technique and also to compete intraoperative and postoperative difficulties of spinal anaesthesia with epidural anaesthesia.

\section{Material and Methods}

A randomized, prospective, comparative trial "To Compare Spinal Anaesthesia Versus Epidural Anaesthesia for inguinal Hernioplasty" was conducted in the anaesthesia department of a tertiary medical Hospital after approval of Institutional Ethics Committee and patient's written and informed consent were obtained. All patients were male, age between 18 to 80 years. The present study included male patients of uncomplicated inguinal hernia with American society of anaesthesiologist (ASA) grade 1 and 2. All patients were admitted for planned surgery; they were examined and preanesthetic check-up done. All patients were explained about the techniques of anaesthesia for hernioplasty and where randomized into two groups. They were operated for inguinal hernioplasty according to recognised surgical guidelines.

The exclusion criteria were negative consent, complex hernias (recurrent, obstructed Hernia, irreducible, incarcerated, bilateral, strangulated), morbid obesity, epilepsy, anticipated problematic intubation and contraindication of Spinal Anaesthesia or Epidural Anaesthesia. Patients with a past history of Coagulopathy and significant cardiovascular, renal, respiratory, hepatic or metabolic disease. Patients with a history of substance abuse, mental dysfunction, active gastrointestinal reflux, chronic analgesic use.

In the operating room patients clarified the technique, monitors were attached and the baseline reading of heart rate (HR), non-invasive blood pressure (NIBP), electrocardiogram, and oxygen saturation $(\mathrm{SpO} 2)$ were documented. Then, intravenous line was placed and patients were pre-loaded with $15 \mathrm{ml} / \mathrm{kg}$ of ringer lactate solution.

Spinal anaesthesia was given under all sterilised precaution, $3 \mathrm{ml}$ of $0.5 \%$ bupivacaine heavy using a 25-gauge Quincke's spinal needle through the L3-L4 intervertebral space in the sitting posture. Before giving the local anaesthesia, each patient throughout the technique asked to report verbally any time if he feels distress.

Epidural Anaesthesia: Under all aseptic precautions, $18 \mathrm{~g}$ Tuohy's epidural needle was employed at L3-L4 intervertebral space in sitting posture by loss of resistance technique. Epidural drug (12 $\mathrm{ml} 0.5 \%$ Bupivacaine) was administered.

All patients were checked for sensory blockade using pin prick technique. Once T6 level of sensory blockade was attained, the surgery was permitted to start. Sensory blockade assessment was done for every $5 \mathrm{~min}$ for the first 1 $\mathrm{hr}$ and then for every $30 \mathrm{~min}$ for the next $3 \mathrm{~h}$. Motor blockade assessment was done by Bromage scale for every $5 \mathrm{~min}$ for the first $30 \mathrm{~min}$ after drug administration.

We collected the patients' preoperative, intraoperative and postoperative information consist of age, gender, site of hernia, body mass index (BMI), duration of surgery, patients' pain intensity at the $3,6,12$, and 24 hours periods after surgery by a visual analogue pain score (VAS), dose of analgesic, any early complications such as hematoma, urinary retention, infection and hospitalization time. To assess pain severity, we asked patients to rate their pain from 1 to 10 and the results were recorded as VAS values.

$0-$ no pain,

1-3: mild pain,

4-6: moderate pain,

7-10: severe pain.

Rescue analgesia was given when VAS scale becomes more than 3. Hemodynamic parameters such as HR, systolic blood pressure (SBP) and diastolic blood pressure (DBP), mean arterial blood pressure (MAP), and $\mathrm{SpO} 2$ were watched at every 5-min. interval until $120 \mathrm{~min}$ then $30 \mathrm{~min}$ interval for further $3 \mathrm{~h}$. Intraoperative hypotension and bradycardia was managed with IV fluids and titrated intra venous doses of Mephentermine $6 \mathrm{mg}$ and atropine of 0.6 $\mathrm{mg}$ respectively. Any complications like nausea, vomiting, pruritus and hypersensitive responses were noted and managed by standard guidlines.

\section{Results}

Demographic data and duration of surgery were comparable in both the groups (Table 1).

Table 1: Intraoperative and postoperative comparison of various parameters

\begin{tabular}{|c|c|c|c|}
\hline & Spinal Anesthesia n=50 (\%) & Epidural Anesthesia n=50 (\%) & p= value \\
\hline ASA Grade (\%) & & & \\
\hline I & $33(66 \%)$ & $35(70 \%)$ & 0.781 \\
\hline II & $16(32 \%)$ & $15(30 \%)$ & 0.690 \\
\hline Mean duration for procedure (Min) & $3.73 \pm 0.67$ & $7.95 \pm 0.41$ & $<0.001$ \\
\hline Onset of action (Min) & $6.22 \pm 1.04$ & $10.567 \pm 0.47$ & $<0.001$ \\
\hline Intravenous fluid requirement (ml) & $1580 \pm 190.1$ & $101.00 \pm 10.20$ & $<0.001$ \\
\hline Duration of surgery (min) & $85.17 \pm 7.82$ & $1(2 \%)$ & 0.019 \\
\hline Block failure (\%) & $0(0 \%)$ & $3(6 \%)$ & 0.013 \\
\hline Intraoperative Hypotension (\%) & $19(40 \%)$ & 0 & 0.004 \\
\hline Urinary retention & $7(14 \%)$ & $1(2 \%)$ & 0.019 \\
\hline Nausea and Vomiting & $05(10 \%)$ & 0 & 0.319 \\
\hline PDPH & $01(2 \%)$ & $3.95 \pm 2.57$ & $<0.001$ \\
\hline Duration of ambulation (hour) & $9.58 \pm 0.82$ & $0 / 33 / 9 / 8$ & $<0.001 *$ \\
\hline Bromage scores (3/2/1/0) $\$$ & $39 / 7 / 4 / 0$ & & \\
\hline
\end{tabular}

Total time taken for performing the procedure was significantly longer with Epidural Anaesthesia than that of Spinal Anaesthesia (7.95 \pm 0.41 Vs $3.73 \pm 0.67$ minutes, $p<$
0.001 ) but onset of action was comparable in both the groups $(6.22 \pm 1.04$ in Spinal Vs $10.567 \pm 0.47 \mathrm{~min}$ in Epidural $p<0.001$ Significant). Intraoperative fluid 
requirement was statistically higher in Spinal than Epidural $(1580 \pm 190.1 \mathrm{ml}$ vs $1021.33 \pm 77.16 \mathrm{ml}) \quad(p<0.0001)$. Duration of Surgery was significantly shorter in Spinal as compared to Epidural $(85.17 \pm 7.82$ vs $101.00 \pm 10.20$ mins.) $(p=0.019) .2 s \%$ patients had failure of Epidural block whereas no Spinal Anaesthesia failed in patients. Systolic and mean blood pressure showed statistically significant reduction in Spinal as compared to Epidural (19(40\%) vs
$3(6 \%))(p<0.001)$. Also, Urinary retention and Post Dural puncture headache (PDPH) was seen only in Spinal Anaesthesia. Whereas 5 patients had nausea and vomiting during spinal and only 1 patients during Epidural Anaesthesia. Duration of ambulation was significantly shorter in Epidural as compared to Spinal $(3.95 \pm 2.57$ vs $9.58 \pm 0.82$ hours $)(p<0.001)$.

Table 2: Operative condition, intra-operative discomfort and satisfaction with anaesthesia

\begin{tabular}{|c|c|c|}
\hline Variables & Spinal Anesthesia (n=50) & Epidural Anesthesia (n=50) \\
\hline \multicolumn{3}{|c|}{ Operative condition } \\
\hline Excellent/Good/Poor & 50 & $45 / 4 / 1$ \\
\hline Intra-operative pain & 0 & 10 \\
\hline Satisfaction with anesthesia & 50 & 40 \\
\hline (Satisfy/Not satisfy) Surgeon Patients & $50 / 0$ & $45 / 5$ \\
\hline
\end{tabular}

In table 2, the surgeons and patients expressed satisfactory result as satisfy in both the groups. The both group of patients declared of having good comfort during surgery, reduced requirement of postoperative analgesia and thereby experience of less side effects. This difference between the groups are statistically insignificant.

Table 3: Post-operative pain (1st 12 hours)

\begin{tabular}{|c|c|c|}
\hline Grade (Time) & $\begin{array}{c}\text { Spinal Anesthesia } \\
(\mathbf{n = 5 0})\end{array}$ & $\begin{array}{c}\text { Epidural Anesthesia } \\
(\mathbf{n = 5 0})\end{array}$ \\
\hline $0-3 \mathrm{hrs}$ & 0 & 0 \\
\hline $4-6 \mathrm{hrs}$ & $26(52 \%)$ & $28(56 \%)$ \\
\hline $7-9 \mathrm{hrs}$ & $31(62 \%)$ & $35(70 \%)$ \\
\hline $10-12 \mathrm{hrs}$ & $42(84 \%)$ & $43(86 \%)$ \\
\hline
\end{tabular}

In table 3, patients operated under Spinal Anaesthesia had less postoperative pain on day -0 (between 4-6 hrs 52\% patients, 7-9hrs 62\%, 10-12 hrs 84\%) compared to Epidural Anaesthesia group (between 4-6 hrs 56\% patients, 7-9hrs $70 \%, 10-12 \mathrm{hrs} 86 \%$ ). There was no significant difference in pain score in both the group of the patients.

Table 4: Intraoperative pain

\begin{tabular}{|c|c|c|}
\hline $\begin{array}{c}\text { Intraoperative pain } \\
\text { (VAS) }\end{array}$ & $\begin{array}{c}\text { Spinal anaesthesia } \\
(\mathbf{n = 5 0})(\boldsymbol{\%})\end{array}$ & $\begin{array}{c}\text { Epidural anaesthesia } \\
(\mathbf{n = 5 0})(\mathbf{\%})\end{array}$ \\
\hline None (VAS=0) & $38(76 \%)$ & $7(14 \%)$ \\
\hline Mild (VAS 1-3) & $6(12 \%)$ & $9(18 \%)$ \\
\hline Moderate (VAS 4-6) & $6(12 \%)$ & $28(56 \%)$ \\
\hline Severe (VAS $>=7)$ & 0 & $6(12 \%)$ \\
\hline
\end{tabular}

In table 4, spinal anesthesia Group, 38(76\%) patients had no pain after inguinal hernioplasty, while 6(12\%) patients experienced mild pain and 6(12\%) patients experienced moderate pain after surgery. None had severe pain. In the Epidural Anesthesia Group, 7(14\%) patients had no pain after surgery, while $9(18 \%)$ patients experienced mild pain and $28(56 \%)$ patients experienced moderate pain after surgery. $6(12 \%)$ patient had severe pain. The difference between the two groups was found to be statistically significant. $(p<0.001)$.

Table 5: Recovery times and adverse events

\begin{tabular}{|c|c|c|c|}
\hline Parameter & Group S (n=50) & Group P (n=50) & $\boldsymbol{P}$ \\
\hline Time to first analgesic (min) & $209 \pm 18$ & $341 \pm 66$ & $<0.001^{*}$ \\
\hline Time to complete sensory regression (min) & $239 \pm 28$ & $476 \pm 92$ & $<0.001^{*}$ \\
\hline Total rescue analgesics (tramadol in mg) & $76 \pm 13$ & $78 \pm 11$ & 0.943 \\
\hline Patients experiencing PONV (\%) & $05(10 \%)$ & $1(2 \%)$ & $<0.001^{*}$ \\
\hline Urinary catheterization & $7(14 \%)$ & 0 & $<0.001^{*}$ \\
\hline Recovery room bypass (\%) & 0 & $20(40)$ & $<0.001^{*}$ \\
\hline
\end{tabular}

Table 6: Post-operative observations

\begin{tabular}{|c|c|c|c|}
\hline Complications & $\begin{array}{c}\text { Spinal Anesthesia } \\
(\mathbf{n = 5 0})\end{array}$ & $\begin{array}{c}\text { Epidural } \\
\text { Anesthesia }(\mathbf{n = 5 0})\end{array}$ & P value \\
\hline Vomiting & $05(10 \%)$ & $1(2 \%)$ & $<0.001 *$ \\
\hline Urinary retention & $7(14 \%)$ & 0 & $<0.001 *$ \\
\hline Headache & $01(2 \%)$ & 0 & $<0.001 *$ \\
\hline
\end{tabular}

In table 6: Only 5 patients in Spinal Anaesthesia group $(10 \%) \& 1$ patients $(2 \%)$ in Epidural Anaesthesia group experienced nausea \& vomiting. The difference was statistically significant. ( $p<0.001)$. In the present study, none of the patients who had urinary retention and headach in Epidural Anaesthesia, while 7 (14\%) of patients had urinary retention and 1 patient had headache after Spinal Anaesthesia. This was statistically significant.

\section{Discussion}

Inguinal hernia repair which is the usual surgery has been done under general, spinal, epidural and local anaesthesia techniques with varying success. As per the latest recommendations of European Hernia Society, in situation of an open repair, local anaesthetic must be considered for every adult patients through a main reducible one-sided inguinal hernia ${ }^{[8]}$. This is a grade A recommendation. Inspite of this, there is great level of inertia in accepting this technique among anaesthesiologists. Inguinal field block is one of the oldest techniques, in practice since decades ${ }^{[9]}$. Primarily, local anaesthesia was given by the surgeon at the site of operation but do not deliver whole anaesthesia. Ilioinguinal and iliohypogastric nerve block offer somatic block over the lower abdomen and visceral pain is 
frequently relieved by giving additional local anaesthetic at the time of sac dissection ${ }^{[10]}$. In this study we evaluated the efficacy, feasibility, safety, advantages and difficulties of Spinal anaesthesia, as compared to Epidural Anaesthesia.

In this study, we perceived shorter anaesthesia onset time in Spinal Anaesthesia (table 1) as compared to Epidural Anaesthesia. These consequences are in consistence with results shown by Davis et al. They see time to attain maximum cephalad extent to be $13 \pm 7 \mathrm{~min}$ in spinal anaesthesia with $0.5 \%$ hyperbaric bupivacaine and $21 \pm 4$ min in epidural anaesthesia with $0.5 \%$ bupivacaine ${ }^{[11]}$.

The mean intraoperative intravenous fluid requirement was significantly higher in Spinal Anaesthesia than Epidural Anaesthesia $(1580 \pm 190.1 \mathrm{ml}$ vs $1021.33 \pm 77.16 \mathrm{ml})$. The higher fluid requirement in Spinal Anaesthesia group is due to of sympathetic blockade, which enlarges the intravascular compartment requiring fast intravascular infusion to keep the good intravascular volume and blood pressure. Consequently, Epidural Anaesthesia can be best technique in patients with low ejection fraction.

There was no block failure during Spinal Anaesthesia. In Epidural Anaesthesia, 1 patient (2\%) was block failure due to insufficient block. In similar analyses revealed by Sultana A et al. ${ }^{[12]}$ and Ruben N Van Veen et al. ${ }^{[13]}$ using standard inguinal field block, intraoperative uneasiness of moderate grade during the dissection of hernia sac in $34 \%$ and $35 \%$ patients respectively. Failure rate for local inguinal field block was $3.33 \%$ as stated by C J Sparks el al. ${ }^{[14]}$ and for local infiltration anaesthesia, it was $3.17 \%$ as described by Aysun Yilmazlar et al. ${ }^{[15]}$ as compared to $10 \%$ in our study. The failure rate can be minimalized with more experience and skill in this technique.

Our results are similarly for confirmation with study showed by Nehme et al. who discovered that the prevalence of Intraoperative hypotension was maximum in spinal anaesthesia (19 patients), ${ }^{[16]}$ whereas it was perceived only in 3 patients of Epidural Anaesthesia, which remained negligible in cases of Epidural Anaesthesia. Comparable outcomes were also revealed by Tingwald and Cooperman [17]. This result is due to the sympathetic blockade produced by spinal anaesthesia, leading to vasodilatation, peripheral venous pooling of blood and reduced cardiac output. Aysun Yilmazlar et al. discovered a significant reduce in mean arterial pressure in spinal anaesthesia group (pre $70.3 \pm 10.3 \mathrm{mmHg}$ and post $52.3 \pm 9.3 \mathrm{mmHg}$ ) and no such decrease in ilioinguinal and iliohypogastric nerve block group $^{[15]}$.

In Spinal anaesthesia (14\%) patient and in Epidural Anaesthesia $(0 \%)$ patients had urinary retention (i.e. full bladder on palpation and failure to micturition 8 hours postoperatively and concomitant with distress). Davis et al. [11] stated in his study competing spinal and epidural anaesthesia stated 7 (out of 32) patients in spinal group and 14 (out of 30) in epidural group who required catheterization. Low occurrence of urinary retention in our study as compared to this due to lower dose of anaesthetic used in spinal group ( $3 \mathrm{mg}$ ) and use of single shot technique for epidural anaesthesia. Furthermore, their mean catheterization time was $4.2 \pm 1.7$ hours in in spinal group and $4.7 \pm 2.3$ hours in epidural group and we waited for at least 8 hours for patient to micturition freely and before that catheterization was done only if indicated clinically.

Despond et al. ${ }^{[18]}$ in his study, Post Dural puncture headache (PDPH) in young orthopaedic patients using $27 \mathrm{G}$ needles (whittcre and Quincke's), found occurrence of 9.3\% in both the groups. In our study only single patient in spinal group developed PDPH which responded sufficiently to intravenous fluids and oral analgesics. Lower occurrence of PDPH is attributable to usage of fine gauze (25 number quincke) needle in our study.

Duration of ambulation was longer in Spinal Anaesthesia as compared to Epidural Anaesthesia (9.58 \pm 0.8 2vs 3.95 \pm 2.57 hours) $(<0.001)$. Song D et al. discovered that time-to-home willingness in Epidural block was shortest (133 $\pm 68 \mathrm{~min})$ as compared to Spinal Anaesthesia $\left(280 \pm 83\right.$ min) ${ }^{[19]}$. Ding Y and White PF also stated that the ambulation time in block group was $(86 \pm 18 \mathrm{~min})$ and fit to discharge time was $(112 \pm 49 \mathrm{~min})^{[20]}$. Goutorbe $\mathrm{P}$ et al. revealed that the mean time till discharge was $6.85 \mathrm{~h}$ in block group and resolved that it must be a ideal method in countries with a low Gross National Product (GNP) like in Africa ${ }^{[21]}$.

The postoperative VAS score was significantly higher in Spinal Anaesthesia as compared to Epidural Anaesthesia. Duration of Postoperative analgesia was significantly longer $(5.163 \pm 0.4542$ vs $3.871 \pm 0.4801$ hours) in Epidural Anaesthesia as compared to Spinal Anaesthesia. Comparable outcomes were also noticed by Sultana A et al. ${ }^{[12]}$ and Tverskoy et al. ${ }^{[22]}$

Postoperative complications - 3 patients had nausea, and vomiting which responded to IV ondansetron, 7 patients developed urinary retention and 1 patients had headache in Spinal Anaesthesia. None of patients in Epidural Anaesthesia had any of these difficulties. Similar consequences were also perceived by Young et al. [23] (urinary retention $14 \%$ ) and Sultana A et al. ${ }^{[12]}$ developed wound haematoma or local infection. Less nausea and vomiting in our study is due to low level selected because nausea and vomiting during regional anaesthesia are more common when sympathetic block beyond sixth thoracic segment ${ }^{[24]}$.

Patient's satisfaction score as noticed telephonically was comparable between two groups. Patients having score of 4 (satisfied) or 5 (very satisfied) were taken as satisfied for the purpose of statistical analysis and it was found that $98 \%$ of patients who received spinal anaesthesia and $96 \%$ of patients who received epidural anaesthesia were satisfied from technique used. Correspondingly, in analysis by Pollock comparing spinal and epidural anaesthesia for outpatient knee arthroscopy stated $92 \%$ patients of epidural group and $97 \%$ of spinal group were also enormously or very satisfied from their anaesthetic technique used ${ }^{[25]}$.

\section{Conclusion}

From the present study, we resolve that spinal block produces an early and significantly more effective analgesia and additional intense motor blockade than epidural block. The haemodynamic variations and side effects following the two techniques are more in Spinal than in Epidural Anaesthesia. Two blocks are different as per total duration of the surgery. Thus, both spinal and epidural anaesthesia can be reasonably used for day care surgery. Spinal anaesthesia with 25 gauze quincke's needle and $3 \mathrm{ml} 0.5 \%$ hyperbaric bupivacaine offers extra benefit of early onset and whole relaxation. Epidural Anaesthesia has less urinary retention, less haemodynamic variability, less incidence of nausea and vomiting, hypotension and ambulation. Hence can be use anaesthesia of choice in elderly patients and CVD patients. 


\section{Reference}

1. Stephenson BM. Complications of open groin hernia repairs. Surgi Clinics of North America. 2003; 83:125578.

2. Jethva J, Gadhavi J. Comparison of herniopla anesthesia v/s spinal anest.

3. Swanstrom LL. Laparoscopic hernia repairs: the importance of cost as an outcome measurement at the century's end. Surgical clinics of North America. 2000; 80:1341-51.

4. Amado WJ. Anesthesia for hernia surgery. Surg Clin North Am. 1993; 73:427-38.

5. Hamol KF, Schneider MC, Ummenhofer W, Drewe J. Transient neurologic symptoms after spinal anaesthesia. Anesth Analg. 1995; 81:1148-53.

6. Pollock JE, Neal JM, Stephenson CA, Wiley CE. Prospective study of the incidence of transient radicular irritation in patients undergoing spinal anaesthesia. Anaesthesiology. 1996; 84:1361-7.

7. Vincent J, Collins. Spinal anaesthesia- principles and spinal analgesics-Physiological effects. Principles of Anaesthesiology: general and regional anaesthesia-third edition. Lea and Febiger, Philadelphia, 1993, 14451516.

8. Simons MP et al. European Hernia Society guidelines on the treatment of inguinal hernia in adult patients Hernia. 2009; 13:343-403.

9. Farquharson EL. Early ambulation; with special reference to herniorrhaphy as an outpatient procedure. Lancet. 1955; 269:517-9.

10. Ponka JL. Seven steps to local anesthesia for inguinofemoral hernia repair. Surg Gynecol Obstet. 1963; 117:115-20.

11. Davis S, Erskine R, James MF. A comparison of spinal and epidural anaesthesia for hip arthroplasty. Can J Anaesth. 1992; 39:551-554.

12. Sultana A1, Jagdish S, Pai D, Rajendiran KM. Inguinal herniorrhaphy under local anaesthesia and spinal anaesthesia--a comparative study. J Indian Med Assoc. 1999; 97:169-70,175.

13. Van Veen RN, Mahabier C, Dawson I, Hop WC, Kok NF, Lange JF et al. Spinal or local anesthesia in lichtenstein hernia repair: a randomized controlled trial. Ann Surg. 2008; 247:428-33.

14. Sparks CJ, Rudkins GE, Agiomea K, Fa'arondos JR. Inguinal field block for adult inguinal hernia repair using a short bevel needle. Description and clinical experience in Soloman island and an Australian teaching hospital. Anaesthesia and Intensive care. 1996; 23:143-48.

15. Yilmazlar A1, Bilgel H, Donmez C, Guney A, Yilmazlar T, Tokat $\mathrm{O}$ et al. Comparison of ilioinguinaliliohypogastric nerve block versus spinal anesthesia for inguinal herniorrhaphy. South Med J. 2006; 99:48-51.

16. Nehme AE. Groin hernias in elderly patients. Management and prognosis. Am J Surg. 1983; 146:25760.

17. Tingwald GR, Cooperman M. Inguinal and femoral hernia repair in geriatric patients. Surg Gynecol Obstet. 1982; 154:704-6.

18. Despond O, Meuret P, Hemmings G. Postdural puncture headache after spinal anaesthesia in young orthopaedic outpatients using 27-gauze needles. Can J Anaesth. 1998; 45(11):1106-1109.
19. Song D, Greilich NB, White PF, Watcha MF, Tongier WK. Recovery profiles and costs of anesthesia for outpatient unilateral inguinal herniorrhaphy. Anesth Analg. 2000; 91:876-81.

20. Ding Y, White PF. Post-herniorrhaphy pain in outpatients after pre-incision ilioinguinal-hypogastric nerve block during monitored anaesthesia care. Can J Anaesth. 1995; 42:12-5.

21. Goutorbe P, Lacroix G, Pauleau G, Daranda E, Goin G, Bordes $\mathrm{J}$ et al. Treatment of inguinal hernia in a difficult environment: feasibility and efficacy of ilioinguinal and iliohypogastric blocks. Med Sante Trop. 2013; 23:202-5.

22. Tverskoy M, Cozacov C, Ayache M, Bradley EL Jr, Kissin I. Postoperative pain after inguinal herniorrhaphy with different types of anesthesia. Anesth Analg. 1990; 70:29-35.

23. Young DV. Comparison of local, spinal, and general anesthesia for inguinal herniorrhaphy. Am J Surg. 1987; 153:560-3.

24. Pittoni G, Toffoletto F, Calcarella G, Zanette G, Giron. GP. Spinal anaesthesia in outpatient knee surgery: 22 gauze versus 25 gauze sprotte needle. Anesth Analg. 1995; 81:73-79.

25. Pollock JE, Mulroy MF, Bent E, Polissar NL. A comparison of two regional anaesthetic techniques for outpatient knee arthroscopy. Anesth Analg. 2003; 97:397-401. 